Submitted tor: 7990 cnpo student Awa. for thsion boieriges..

FOR THE REVERSEO-FIELD PINCH REACTOR (KFPR)*

by .

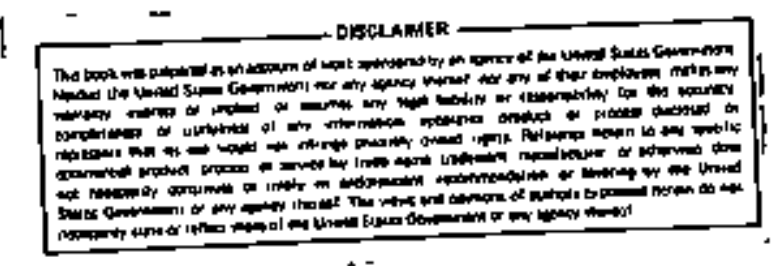

R. A. Mebel, G. H. Mi ley and R. W. Moses T

Fusion Studies Laboratory, Wuclear Engineering Program

University of Illinois, Urbana, I11inois 61801

ABSTRACY

Conceptual fusion reactor designs of the Reversed-field

Pinch Reactor (RFPR) have been based on profile-averaged zero-dimensional (point) plasma models. The plasma response/performance that has been predicted by the point plasma model is re-exarined by a comprehensive onedimensional (radial) burn code (RFPURN) that has been developed and parametrically evaluated for the RFPR. The RFPR plasma parameters have been optimized and effects of turbulent transport and stability have been studied.

\title{
I. INTROOUCTION
}

A comprehensive conceptual design of a Reversed field Pinch (RFP) reactor was recently published. 1 The plasina physics model, used to estimate the thermonuclear burn dyramics for this study was based on a zero-dimensional or "point-properties" formulation. This "point" model averaged all crucial plasma properties (i.e., field, density, and temperature profiles) in accordance with the Bessel-function model 2,3 for magnetic field profiles.

*Work supported by US DOE contracts EY-76-S-02-2218 and lx-7405-EHG-36 tos Alamos Scientific Laboratory 


\section{DISCLAIMER}

This report was prepared as an account of work sponsored by an agency of the United States Government. Neither the United States Government nor any agency Thereot, nor any of their employees, makes any warranty, express or implied, or assumes any legal liability or responsibility for the accuracy, completeness, or usefulness of any information, apparatus, product, or process disclosed, or represents that its use would not infringe privately owned rights. Reference herein to any specific commercial product, process, or service by trade name, trademark, manufacturer, or otherwise does not necessarily constitute or imply its endorsement, recommendation, or favoring by the United States Government or any agency thereof. The views and opinions of authors expressed herein do not necessarlly state or reflect those of the United States Government or any agency thereof. 


\section{DISCLAIMER}

Portions of this document may be illegible in electronic image products. Images are produced from the best available original document. 


\section{- ᄂ'-}

In order to verify the accuracy of these studies and explore other phenomena, a more reaitstic one-dimensional (radial) plasma model has been developed and applied to the point design reported in Ref. 1 . The results of this comparison and suggested changes inferred for future PFPR designs are reported herein.

\section{BACKGROUNO}

The RFP is a device similar to a tokamak in structure. It is toroldal and has continement provided by toroidal $\left(\mathrm{B}_{\phi}\right)$ and poloidal $\left(B_{\theta}\right)$ magnetic fieids. The tnajor difference is that $B_{\phi}$ and $B_{\theta}$ are the same order of magnitude and $B_{\phi}$ is reversed on the outside edge of the piasma (see figure 1).1

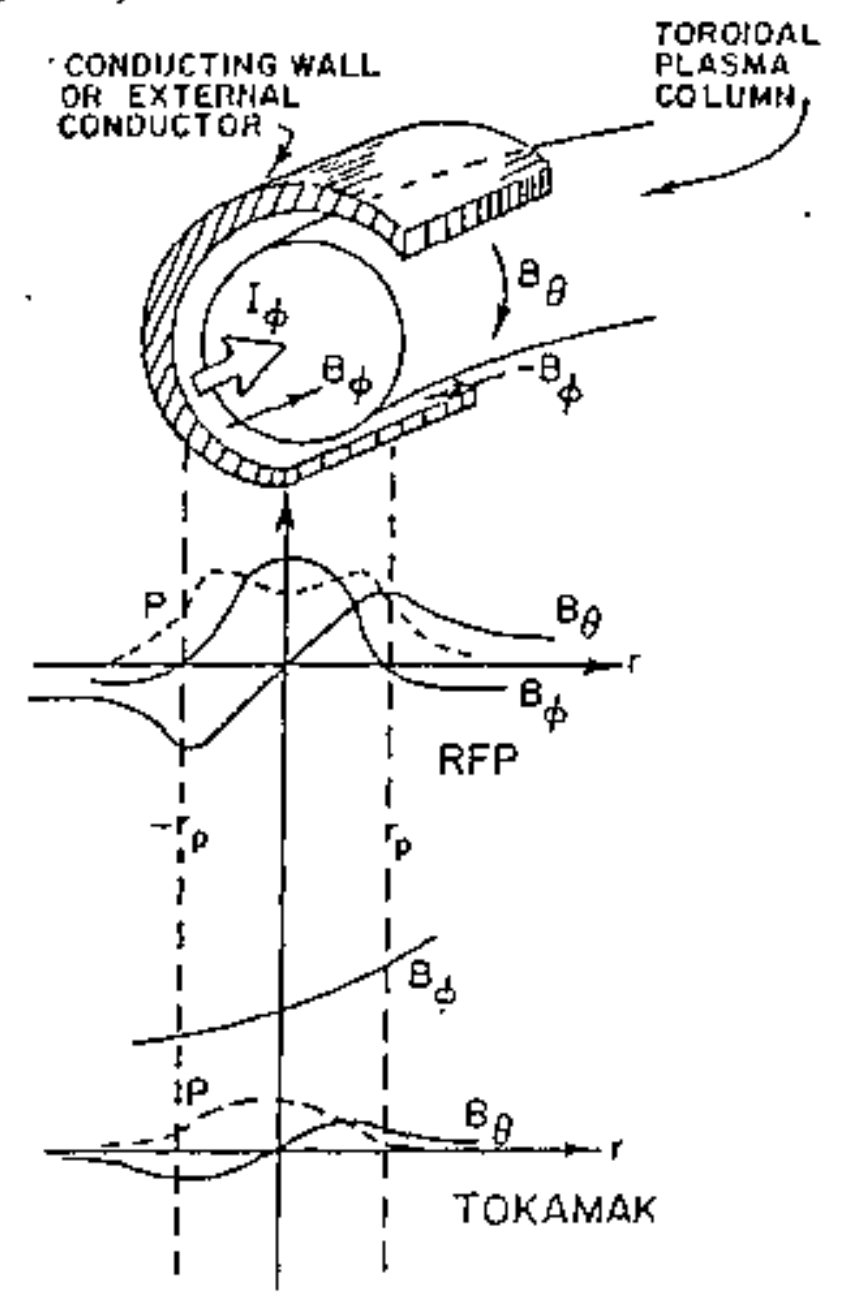

FIGURE 1

Comparison of magnetic and pressure profites for a $d q / d r \neq 0$ stabilized RFP and a $q>i$ stabilized tokamak. 
The resulting high shear provides stability to high $B\left(B_{0}-.5\right)^{5}$ for pressure driven modes while a conducting wall stabilizes current driven modes. Unlike tokamaks which require $q .>1\left[q=\left(r_{p} / R\right)\left(B_{q} / B_{E}\right)\right]$ the RFp operates with $q<i$ and hence has no aspect ratio constrafnt.

Since $\mathrm{B}_{\theta}-\mathrm{B}_{\phi}$, the RFP has large currents and the reactor can be fgnited by ohric heating alone. This feature, coupled with stability at high $B$ and the lack of an aspect ratio constraint, potentialiy provides signiflcant engineering advantages over tokamaks. However, since $B_{\phi}$ resistively decays, the RFP must operate in a pulsed mode. Still the resistive decay time is long enough at thermonuclear temperatures to allow pulse times on the order of tens of seconds so that, as shown later, favorable energy balances are possible.

Previous plasma studies of RFPR have been done using a point model. (A detailed description of this work is given in Reference 1). Transport coefficients were assumed to be classical, except for thermal conduction which was assumed to be anonalous (J/200 Bohm). This is consfistent with the results seen on Zeta, where energy confinement was strongly anoinatous even during the "quiescent" period. 6

Results of the cost optimized point model RFPR design are summarized in Table I. These parameters are the base case values used for the one-dimensional simulations.

\section{ONE-DIMENS IONAL RFPR THERMONUCLEAR BURN}

The one-dimensional model developed here treats a three-species quasi-neutral gas of electrons, OT-jons and alpha particles. Radial field diffusion and plasma convection in this axisymetric system are 
TABLE I'

SWMARY DESCRIPTION OF RFPR. DESIGN PARAMETERS

VALUES

First-wall radius, $r_{w}(m)$

1.5

Major radius, $\mathrm{R}(\mathrm{m})$

12.7

Toroidal plasma current, $I_{\phi}$ (MA)

20.0

Toroidal rield at the coll, $B_{\phi c}$ (T)

2.0

Poloidal field at the coil, $B_{\theta c}(T)$

2.0

Toroidal coil energy, $W_{B_{\phi}}(G J)$

3.7

Poloidal coil energy, $W_{B \theta}(G J)$

11.0

Field rise time, $\tau_{R}(s)$

0.1

Burn time, $T_{B}(s)$

21.6

cycle time, $t_{c}(s)$

26.6

Average fuel burnup, $f_{B}$

0.5

Average plașa density, $n\left(1 / \mathrm{m}^{3}\right)$

$2.0(10)^{20}$

Average plasma temperature, $T_{i, e^{(k e V)}}$

15.0

14.1-WeV neutron flux at first wail, $\left.I_{W}\left(\mathrm{MW} / \mathrm{m}^{2}\right)^{2}\right)$

2.7

Engineering Q-vaiue, $Q_{E}$

5.8

Recirculating power fraction, $E=3 / Q_{E}$

0.17

Average blanket power density, $\mathrm{P}_{\mathrm{BLK}}\left(\mathrm{kH} / \mathrm{m}^{3}\right)$

4.7

Average system power density, $\mathrm{P}_{S Y S}\left(\mathrm{~m}^{3} \mathrm{~m}^{3}\right)$

0.9

Total thermat power, $P_{T H}($ MWt $)$

3000

Het electrical power, $P_{E}$ (MWe)

750

Het plant efficiency, $n_{\mathrm{p}}=n_{\mathrm{TH}}(1+\varepsilon)$

0.25 
modeled under a magnetohydrostatic approximation, and themal conduction for jons and electrons are computed separately. The plasia is heated ohmically, and radiation losses include breristrahlung and electron cyclotron. Alpha particle heating is modeled using an in-situ approximation with the power fractions going to ions and electrons determined by Ref. 7 .

\section{A. Radial Transport}

The radial burn code uses an implicit Lagrangian meshing technique that has been developed specifically for modeling plasma processes quasi-statically. Inertial terins in the MliD equations are ignored, and plasma evolution is then determfned by pressure balance, $J \times \vec{B}=\nabla \rho$. This requires that the equilibrium profiles are stable, and this assumption is examined periodically by a separate algorithm (see Sec. IIIC). For systems that exhibit symetry in $\theta$ and $\phi$, the pressure balance constraint is expressed by the following integral equation:

$$
p+B^{2} / 2 \nu_{0}-\left(2 / r^{2}\right) \int_{0}^{5}\left(p+B_{\phi}^{2} / 2 u_{0}\right) r^{\prime} d c^{\prime},
$$

where $\mathrm{g}$ is the total plasma pressure, $\mathrm{B}^{2}=\mathrm{B}_{\phi}^{2}+\mathrm{B}_{\theta}^{2}$, and uks units are consistently used except for temperature, $T(k e V)$. 
Plasma paraneters are computed as functions of time by a two-step method. First, the Lagrangian mesh is fixed in space for the computation of all diffusion, radiation, and heating processes. Next, the Lagrangian mesh is adjusted radialiy to satisfy the pressure balance constraint given by Eq. (1).

The first phase of this two-step process is described by the following expressions for ion dersity $n_{i}$, alpha-particle density $n_{c}$, energy of the $j$ th species $T_{j}(j=e, i, \alpha)$, and inagnetic field.

$$
\begin{aligned}
& \frac{\partial t_{i}}{\partial t}+\vec{\nabla} \cdot \vec{\Gamma}_{1}=s_{d}-2 f(1-f)\langle\sigma v\rangle n_{d}^{2} \\
& \frac{\partial n_{a}}{\partial t}+\vec{\nabla} \cdot \vec{\Gamma}_{a}=f(1-f)\langle\sigma v\rangle n_{i}^{2} f_{a} \\
& \frac{3}{2} n_{j} \frac{d r_{j}}{d T}+p_{j} \vec{\nabla} \cdot \overrightarrow{\Gamma_{j}}=-\vec{\nabla} \cdot \vec{q}_{j}+Q_{j}
\end{aligned}
$$

The fluid velocity with respect to the Eulerian coordinates is $v, r_{j}=n_{j} v_{j}$ is the particle flux, $s_{j}$ is a refuel ion source term, $f$ is the trition fraction, and $f_{\alpha}(\leq 1.0)$ is an alpha-partfcie confinement efficiency based on finite orbft effects. The thermat heat flus is $\vec{q}_{p} ; a_{j}$ is a heat source/sink including alpha heating, ohis heating, ion-eiectron equilibration, bremstrahiung and cyclotron 
radiation; and $\mathrm{R}_{\mathrm{TH}}$ is a thermat force. The parallel and perpendicular resistivities, $\eta_{\pi}$ and $n_{\underline{l}}$, are treated either classically or with anomalous effects included as described tater (sec Sec. III0).

\section{B. Pressure Balance}

When the transport (Eqs. (2a-d)) is evaluated for a given time step at each radial position, the new valises of temperature, density and ffelds do not satisfy pressure balance (Eq. (1)). It is then necessary to adiabatically adjust the Lagrangian mesh so the new radial positions satisfy the pressure constraint. This procedure is subject to the appropriate boundary condition(s), e.g. maintaining a given piasma radius or toroidal current. Variable time steps are used to assure fast convergence, while energy halance is used to check the accuracy of the model.

\section{Stability Modele?}

Two methods are used to monitor the ideaf MHD stability. Local modes are assumed to saturate and are monitored using a Suydam criterion. ${ }^{8}$ A Rayleigh-Ritz type energy principle is used to monitor global modes. Both methods for monitoring stabitity are derived from the idea I MHD equations using a cylindrical approximation.

In one-dimension the energy principie assumes the following form 9

$$
\delta\left(\sqrt{ }=(n / 2) \int_{0}^{r} p\left[f(d \xi / d \tau)^{2}+g s^{2}\right] d r \quad\right.
$$


where

$$
\begin{aligned}
& f=\frac{r\left(k r B_{p}+m B \theta\right)^{2}}{H_{0}\left[(k r)^{2}+m^{2}\right]} \\
& g=\frac{2(k r)^{2}}{\left(m_{1}\right)^{2}+1 t^{2}}\left(\frac{d \theta}{d r}\right)+\frac{\left[k r b_{0}+m B_{\theta}\right]^{2}\left[(k r)^{2}+m^{2}-1\right]}{\left.\nu_{0} r(k r)^{2}+m^{2}\right]} \\
& +\frac{2(k r)^{2}\left[(k r)^{2} 1 b^{2}-m^{2} B b^{2}\right]}{u_{0} r\left((k r)^{2}+m^{2}\right)^{2}} .
\end{aligned}
$$

The axial wave number is $k$, the mode number is $\mathrm{m}$, and $\xi$ is the radial displacement. The transform $\psi=\xi \sqrt{\bar{f}}$ is employed in order to avoid the singularity in $\xi$ when $f$ approaches zero. ${ }^{5}$ Then Eq. (3) transforms to

$$
\begin{aligned}
& \delta W=(\pi / 2) \int_{0}^{r} p(d \psi / d r)^{2}-(\psi / \theta)(t / f / t \tau)(d \omega / d r)+ \\
& \left.\left[(d E / d r)^{2} / 4 E^{2}+g / r\right] \gamma^{2}\right] d r .
\end{aligned}
$$

The parameter $\psi$ is then expanded into a Fourier Series according to

$$
\psi=\sum_{1=0}^{n} c_{1} \sin \left(a_{i} r\right)
$$

where $\alpha_{i}=(i+1) \pi / r_{p}$. The constant $c_{0}$ is normalized to unity and the remaining constants, $C_{i}(i=1, \ldots, n)$, are computed to minimize the energy $E W$ by requiring that $3 \delta W / \partial c_{j}=0$ for $i=1, \ldots, n$. The resulting set of $n$ inhomogeneous equations in $n$ unkowns is inverted and solved for $c_{i}$. If the resulting value of $b \mathrm{~W}$ is negative, the associated plasma 
configuration is considered unstable. This check is applied to m=0, $k \rightarrow 0$ and $m=1,-30 / R<k<30 / R$, since the long wavelength modes are typically the most unstable. 5

In general, $\partial \delta W / \partial C_{i}=0$ only provides a stationary solution rather than a minimum for the energy principle. A minimum requires that $\partial^{2} \delta \mathrm{b} / \partial C_{i}^{2}>0$ also. However, if $\partial^{2} \delta w / \partial C_{i}^{2}<0$, it can be shown that the plasma is always unstabie and the required answer is provided without inverting the matrix.

The Suydam criterion is included in the more generat energy principle stated by Eq. (3). These Suydam modes, however, have eigenfunctions that are asymptotically singular at rational surfaces. Since the mesh size used by the one-dimensional computation is finite and determined by the previousiy described transport computation, eigenfunctions that are more localized than the mesh size will not be detected by the global energy-principle analysis. Consequently, the global stability anaiysis is able to find gross modes that may also occur simultaneousiy with Suydan modes (which are assuried to saturate). The giobal energy-principle analysis also quantifies the validity of the assumption that Suydam modes are localized in that the modes will be detected if the associatad eigenfunctions extend over a "macroscopic" (f.e., mesh size) volume of the plasma.

\section{AnomaJous Transport}

As will be shown, a large region of the plasma is found to be unstable to local suydam modes for the plasma conditions selected for the point plasma operating parameters. The resulting instabilities are assumed to remain localized and to be manifested as enhanced transport. 10 Specificaliy, the perpendicular resistivity, $\eta_{l}$, was modified relative to the classical value, $n_{L_{c}}$, according to

$$
n_{L}=n_{1 c}+f_{1} \cdot \hat{E}_{s} c B^{2} n_{13} / \pi_{e} \text {. }
$$


where $f_{T}$ is a triangular function that spreads the region of entanced transport over mesh points $(-10$ Larmor radji) adjacent to the location of Suydam instability, $c=10^{-4}$, and $f_{\$}$. is given by

$$
\begin{aligned}
& f_{s}=\left\{\begin{array}{cc}
0 & \text { if } c<1 \\
(\epsilon-1) / \varepsilon \text { if } \epsilon>1
\end{array}\right. \\
& \varepsilon=-\frac{d p / d r}{\left(B_{u}^{2} / 8 r \omega_{0}\right)(d p / d r)^{2}}
\end{aligned}
$$

and

$$
P=\tau_{\phi} / B_{O}=1 / v \text {. }
$$

Bohmllike transport scaling ts used since it scales like to MHD turbulence. 10 The triangular function, $f_{T}$, accounts for the wioth of a Suydam mode while $f_{s}$ is a function varying from 0 to 1 which provides a measure in the degree of Suydan violation. The exact scaling of the perpendicular resistivity has been found to be relatively unimportant as long as it substantially exceeds (by 2 to 3 orders of magnitude) the classical values. The higher perpendicular resistivity increases radial transport of particles and energy, thereby reducing the pressure gradients that initiated the instability.

\section{RESULTS}

Plasma performace was evaluated for four cases:

Case A: The one-dimensional model was forced to follow exactiy the radius trajectory predicted by the zero-dimensional model.

Case 8: The more physicaliy correct assumption of constant radius and moderately programed toroidal current was examined.

Case C: With the plasma radius fixed, regions of Suydam insta. bility were subjected to enhanced transport in order to model a flattening of the pressure profile $(\mathrm{e} . \mathrm{g}$. , Eqs. (8)).

Case D: Using Case B parameters, the magnetic field was varied to opt imize $Q_{p}$. 
For all cases the radial energy confinement time is set equal to 200 Bohn times and it is assumed that both the alpha-particle energy and mass are deposited at the place of birth. Table II sumarizes the essential elements of the three sitiulation cases described above.

\section{TABLE II}

SUNMARY OF CONDIT IONS ASSUMED FOR ONE-DIMEEISIOLIAL SIMULATIOUS

\begin{tabular}{|c|c|c|c|}
\hline Case & $\begin{array}{l}\text { Radius } \\
\text { Trajectory }\end{array}$ & $\begin{array}{l}\text { Energy } \\
\text { Iransport } \\
\end{array}$ & 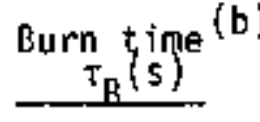 \\
\hline$A^{(a)}$ & moving & 200 & 21.6 \\
\hline B & fixed & 200 & 25 \\
\hline C & fixed & $\begin{array}{l}200 \\
\text { plus Suydam } \\
\text { Turbulance } 10\end{array}$ & 25 \\
\hline D & fixed & 200 & 21.6 \\
\hline
\end{tabular}

(a) closest simulation of zero-dimensional model

(b) quench time taken as $5 \mathrm{~s}$

A. Discussion of Case A Resirlts.

In order to match the point model as close as possible, the plasma radius was confined to a trajectory $r_{p}(t)$ given by

$$
\left.r_{p}(t)=r_{p}(t=0) / \sqrt{1-r_{\theta}(t)}\right)
$$


where the plasma radius $r_{p}$ is defined by the toroidal field reversal point, and $B_{g}$ is the ainflam poloidal beta. The initial temperature distribution was assumed uniform, and the initial density and toroidal fieid profiles within the plasma region were modeled by Bessel functions (consistent with the point modelt)

$$
\begin{aligned}
& n(r, t=0)=n(r=0, t=0) J_{0}^{2}(0.94 a r) \\
& B_{\phi}(r, t=0)=B_{\phi}(r=0, t=0)
\end{aligned}
$$

where $\alpha=2.405 / r_{p}(0)$. The initiat poloidal field profile is computed to satisfy pressure balance.

Figure 2 compares the averaged ion and electron temperatures obtained with the one-dimensional model for Case A with the predictions of the zero-dimensional modet. Shown also is the time dependence of poloidal beta, $B_{\theta}$, and the fractional burnup. The radial dependence of temperatures and fields at $t=12 s$ into the burn is depicted in Fig. 3 . Fjg. 4 shows the density profile, the shear parameter(Eq. (8c)) , P and the Suydam parameter, $f_{5}$ (Eq. (8a)) at 12 seconds. For the parameters shown, $f_{s}>0$, everywhere so the plasma is unstable to local Suydar modes over its entire volume. Fig. 5 compares the neutron, transport, and radiation energy flux at the first walt.

The differences between the point and one-dimensional models illustrated in figs. 2-5 can be attributed to the self-consistent profiles contained in the ofe-dimensional code. The point model assumes a uniform plasma temperature, while the one-dimensional code has radially varying temperatures which are higher and cause enhanced 

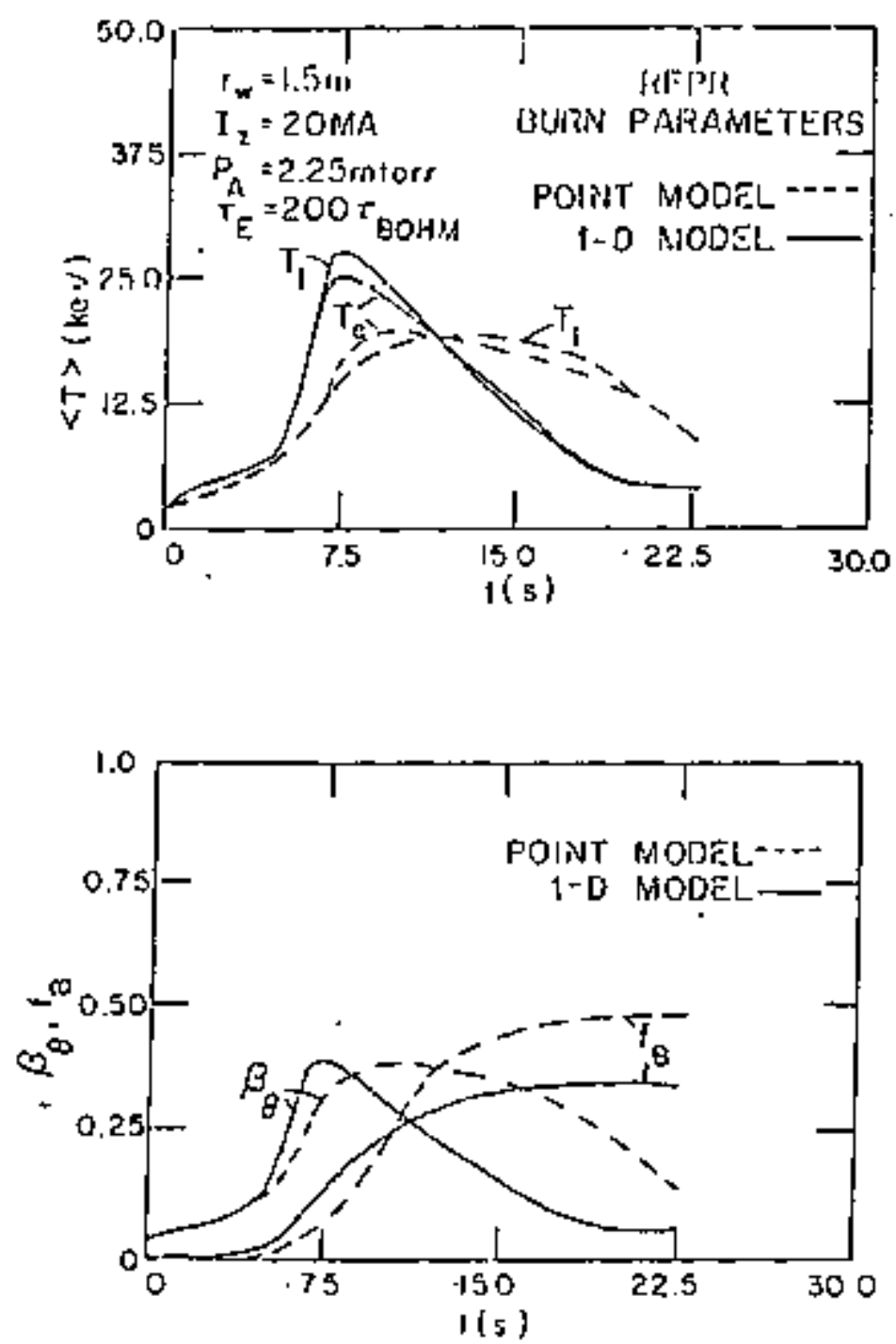

FIGURE 2

Comparison of averaged parameters versus time as predicted by the Case A one-dimensional simulation and the zero-dimensiona? mode?. 

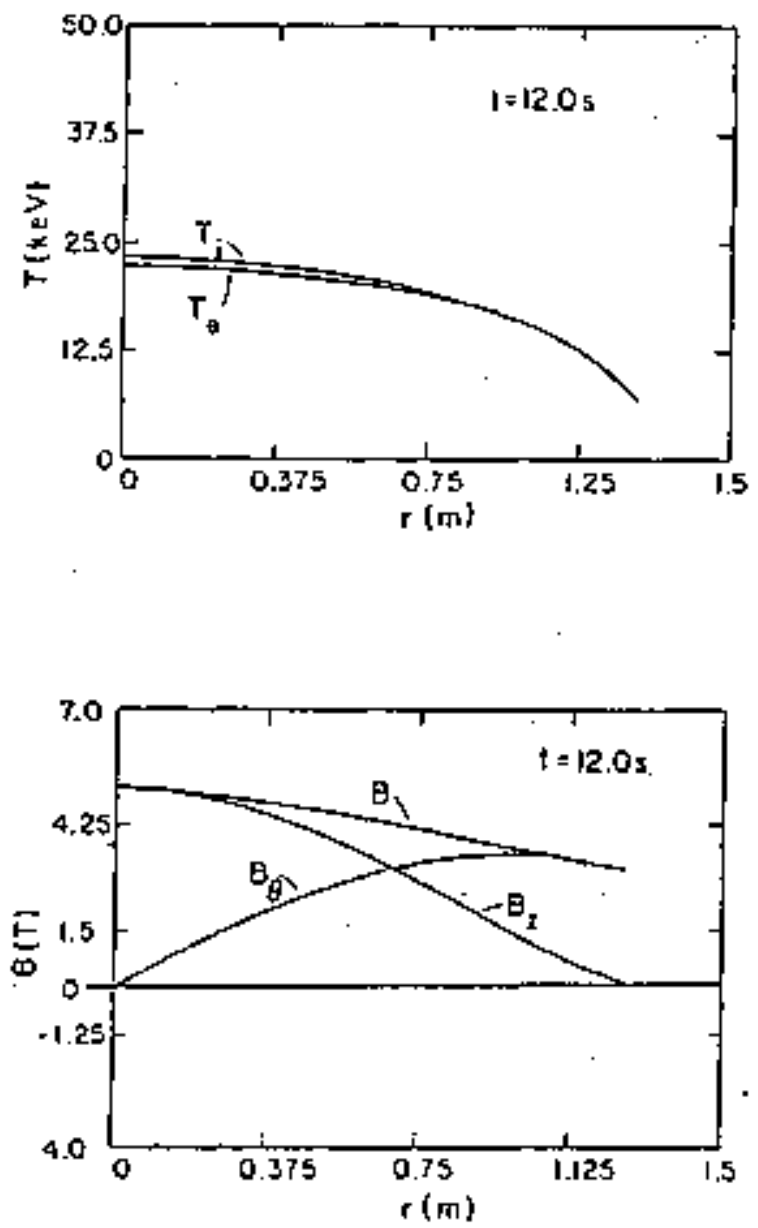

FIGURE 3

Temperature and field profiles for the Case A simulation at 12.0 s into the burn phase. 

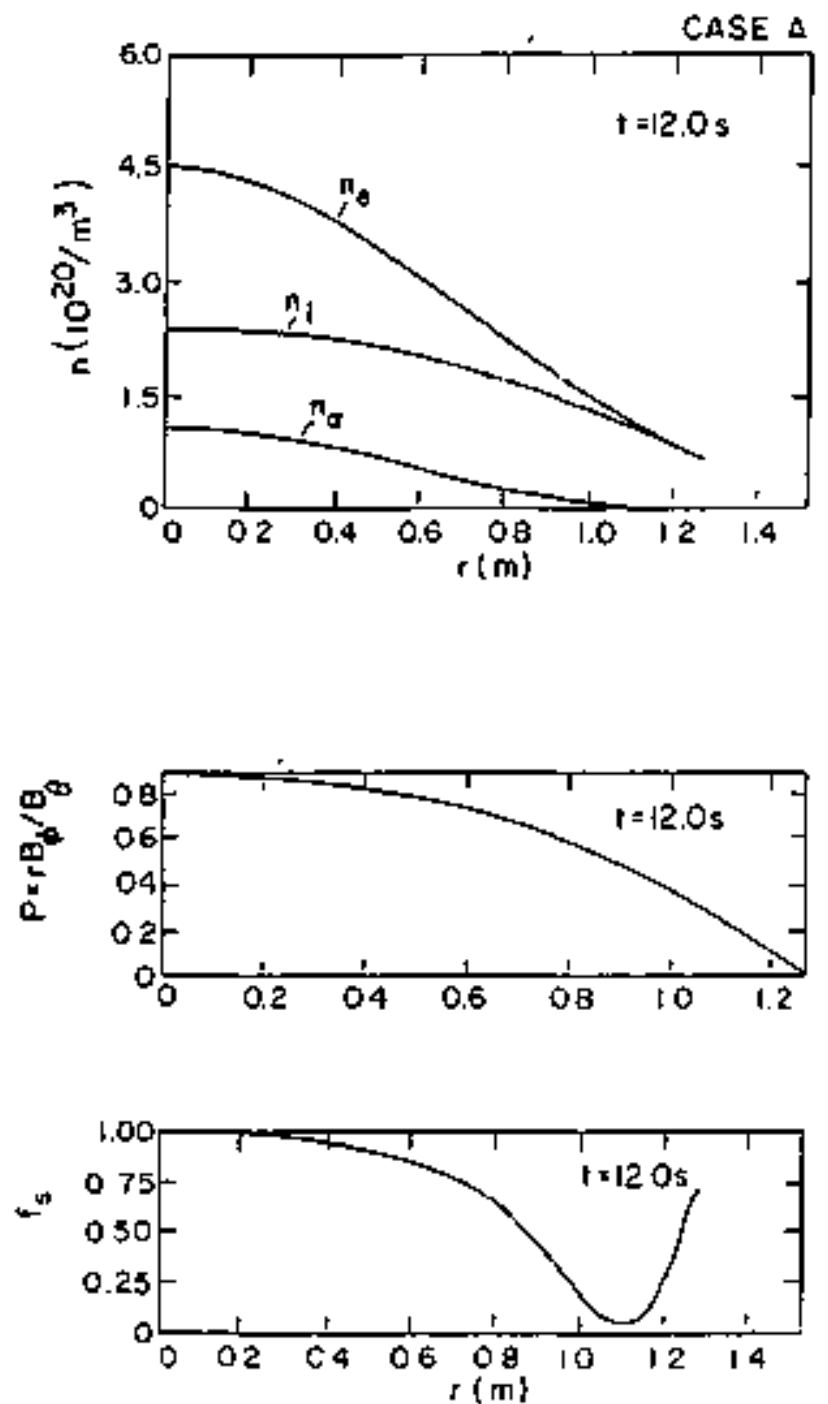

FIGURE 4

Profiles of density, pitch parameter $P$, and suydam parameter, $f_{5}$, for the Case $A$ simulation at 12.0 s into the burn phase. 


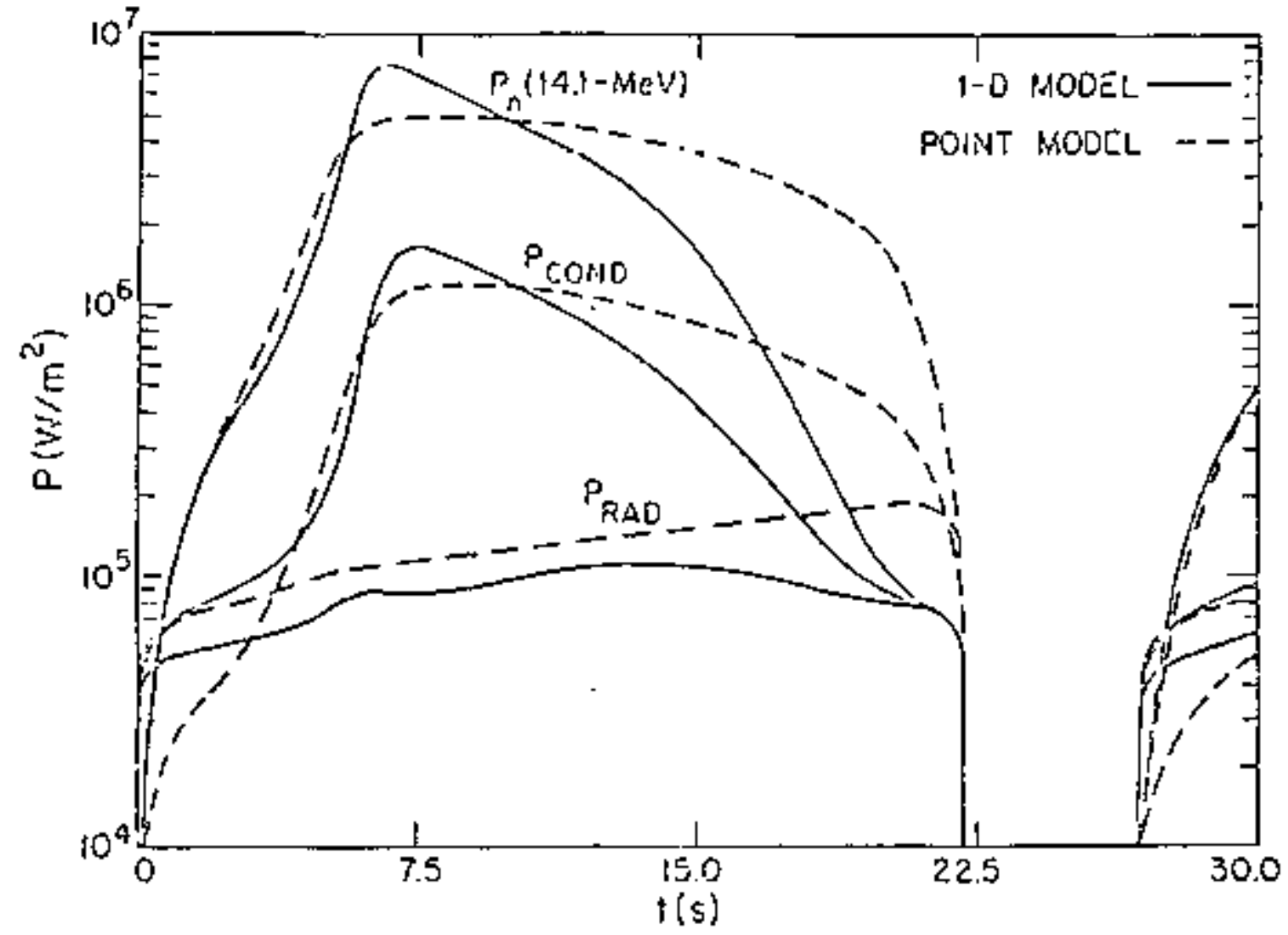

FIGURE 5

Comparison of first-wall neutron, thermat conduction, and radiation fluxes for the Case $A$ one-dimensionat simulation and the zero-dimensional model. 
fusion reactivity (and alpha-particle heating) in the central plasma reyion. This results in a higher average temperature shortly after ignition (Fig. 2). The one-dimensional montel burns out more rapidly, and has a lower value for $f_{B}$ (Fig. 2). 'This lower burnup is principally caused by small burnup near the plasma edge where the plasma is cooler.

The point burn model must specify a magnetic field profile to assure pressure balance and does not account for resistive decay of the toroidal field $g_{\phi^{*}}$ In forcing a radius trajectary, $r_{p}(t)$, the one-dimensionat model forces the toroidal current, I, to decay, as resistive losses consume $B_{\phi}$ field. This results in somewhat less ohmic heating, although this effect is smal].

The radial profiles shown in figs. 3 and 4 remain relatively unchanged throughout the burn period. Both the tenperature and pressure show a maximur on the plașa centertine because of the assumed Bohn-like thermal conduction. However, since the bulk plasma is unstable to suydam modes, enhanced transport occurs in this region. This is examined in case $C$.

Table III sumarizes performace garameters for both the zerodimensional and Case A one-dimensional simulations. of particular jnterest is the plasind Q-value, $Q_{p}$,

$$
Q_{p}=1.25 \cdot W_{N} /\left(W_{O H A}+W_{p f}\right)
$$

It is seen that for the conditions under which Case A was evaluated, a factor ${ }^{T} .5$ decrease in $Q_{p}$ relative to the point model is predicted. This significant difference in $g_{p}$. illustrates the net influence of profile effects, with the reduction in $Q_{p}$ a direct result of the lower fusion yield. However, as for any model, $0_{p}$ values are sensitive to modelistic assumptions. Some of the assunptions are exanined further in the following cases. 
TABLE III

COMPARISON OF ENERGY BALANCE FOR ZERO- AHO ONE-DIMENSIONAL BURM MOOELS

PARAMETER (MJ/MI)

Burn time $\tau_{B}(s)$

Initial plasma energy, $W_{p i}$

Finai plasma energy, $W_{p f}$

Radiation energy, $W_{R A D}$

Ohmic heating energy, $w_{\mathrm{OH}}$

Plasma energy loss (conduction), W COMD

Plasma expansion energy, $W_{p V}$

Magnetic-ffeld energy inside first

wall at end of burn cycle, $W_{B f}$

Fusion Meutron Energy, $W_{N}(14.1 \mathrm{HeV})$

$\cdot 0_{p}=$ (fusion energy)//ohusic +

field energy)
ŻEKO-D

ONE- $D^{\mathrm{a}}$

CASE A

21.6

21.6

0.05

0.7

2.5

1.9

28.7

14.3

7.1

8.9

147.5

93.0

0.7

1.1

51.6

45.0

74.4

9.5

aradius forced to follow zero-dimensional case 
B. Comparison of Constant Radius Cases With and Without Enhanced Transport, Cases $B$ and $C$.

The one-dimensional model was evaluated for a programined rather than a constant toroidal current, using the formalism for Suydam turbulent transport represented by Eqs. (7) and (8). A comparison for the constant radius case with and without Suydan turbulence is given in Fig. 6 , where the time dependence of average temperature, $\beta_{\theta}$, and $f_{5}$ is given. Typical radid profiles of temperatures and fields are depicted in Fig. 7. Like the global parameters in Fig. 6, Suydam turbulent transport has little effect on the temperature and field profiles. Fig. 8 gives the radfal dependence of denstities and the Suydam parameter, $f_{5}$. Key plasma parameters for Cases B and C are summarized in Table IV.

Even without Suydam turbulent transport a greater fraction of the plasma volume becomes Suydan stable (fig. 8) for the constant-radius Case B. Suydam turbulence causes anomalous Bohm-like transport to occur in unstable regions (Eq5. (7) and (8)), flattening the density profiles in the center of the plasma. There is a similar leveling of the pressure profile, pushing the plasma towards the marginal Suydam stability limit.

Comparison of the Suydan stability parameter, $f_{s}$, for Cases $B$ and $c$ shows that enhanced transport changes the plașa from one of uniform Suydam instabifity to a pointwise, stochastic violation of the suydan criterion. As an unstable plasma region is stabitized by anomalous transport, pressure gradients in. adjacent regions are increased, causing these latter regions to become unstable. The net result is a randomized or statistical violation of the Suydan criterion in regions 
TABLE I'y

COMPARISON OF ENERGY BALANCE FOR NONTURBULENT ANO TURBULENT TRANSPORT

PARAPETER (MJ/A ) 1

Burn time $\tau_{B}(s)$

Initial plasma energy, Wi

Final plasma energy, $W_{p f}$

Radiation energy, $W_{R A D}$

Ohricic heating energy, $W_{O H M}$

Plasma energy loss (conduction), "coso

plasma expansion energy, W

Magnetic-field energy inside first

wall at end of burn cycle, Wf

-Fusion Neutron Energy. $\mathrm{W}_{\mathrm{N}}(14 . \mathrm{i} \mathrm{MeV})$

$n_{p}=$ (fusion energy)/(ohmic + field energy)

\begin{tabular}{rr} 
ONE - $0^{\mathrm{a}}$ & \multicolumn{1}{r}{ ONE $-D^{\mathrm{b}}$} \\
CASE 8 & CASE C \\
\hline 24.6 & 25.0 \\
0.8 & 0.8 \\
3.0 & 3.1 \\
14.8 & 13.9 \\
10.4 & 12.4 \\
115.2 & 114.5 \\
0.0 & 0.0 \\
45.1 & 45.5 \\
493.5 & 469.7 \\
11.7 & 10.1
\end{tabular}

aixed plasma radius, no suydan turbulence

bijed plasma radius, Suydar turbulence 

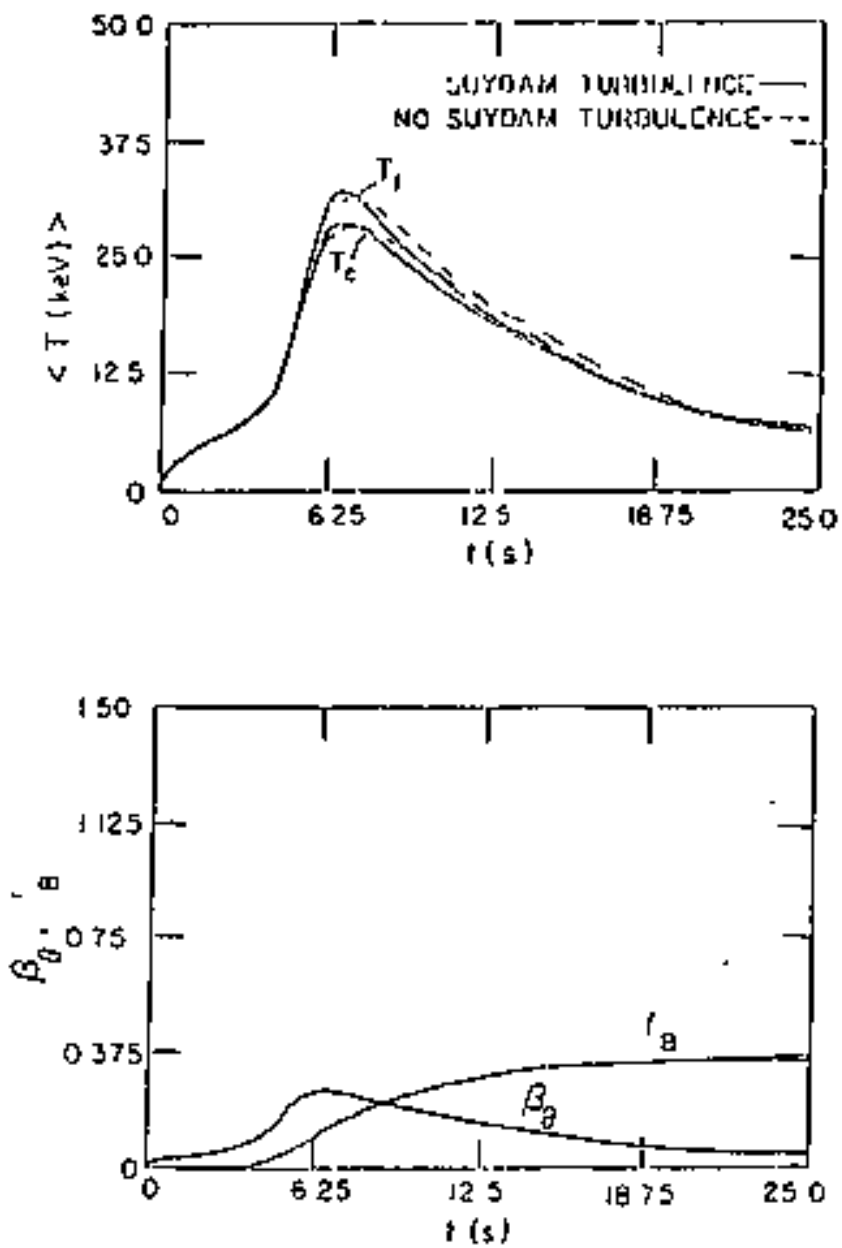

FIGURE 6

Comparison of Case B and Case C one-dimensional simulations 6howing the influence of Suydam turbulence on the average temperatures; poloidal beta, and burmup fraction. For $f_{B}$ and $B_{\theta}$, no difference was observed. 

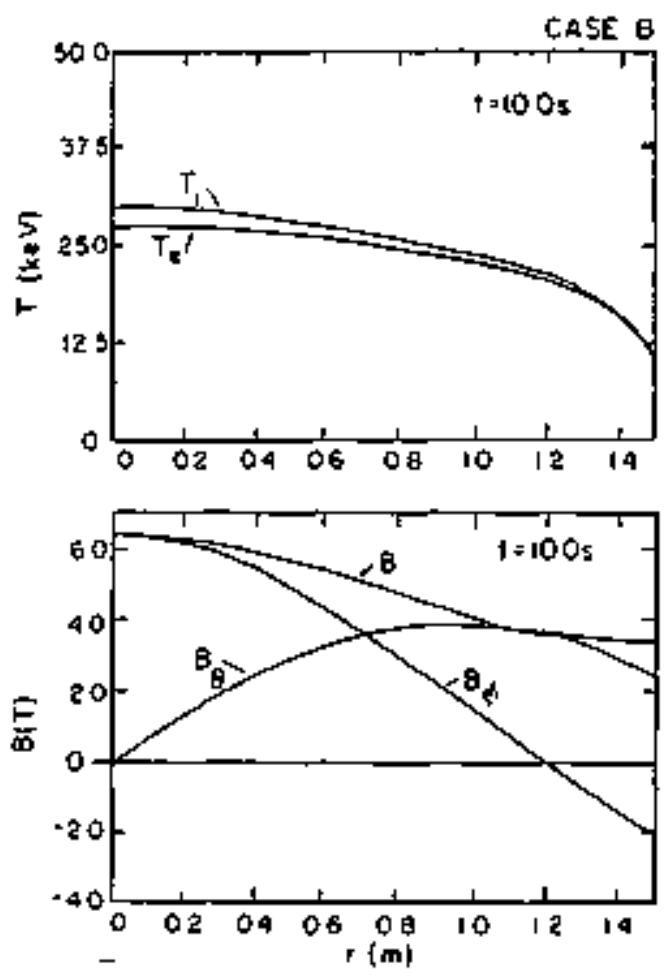

FIGURE 7

Typical temperature and field profiles at $t=10 \mathrm{~s}$ for Cases $\mathrm{B}$ and $\mathrm{C}$. 

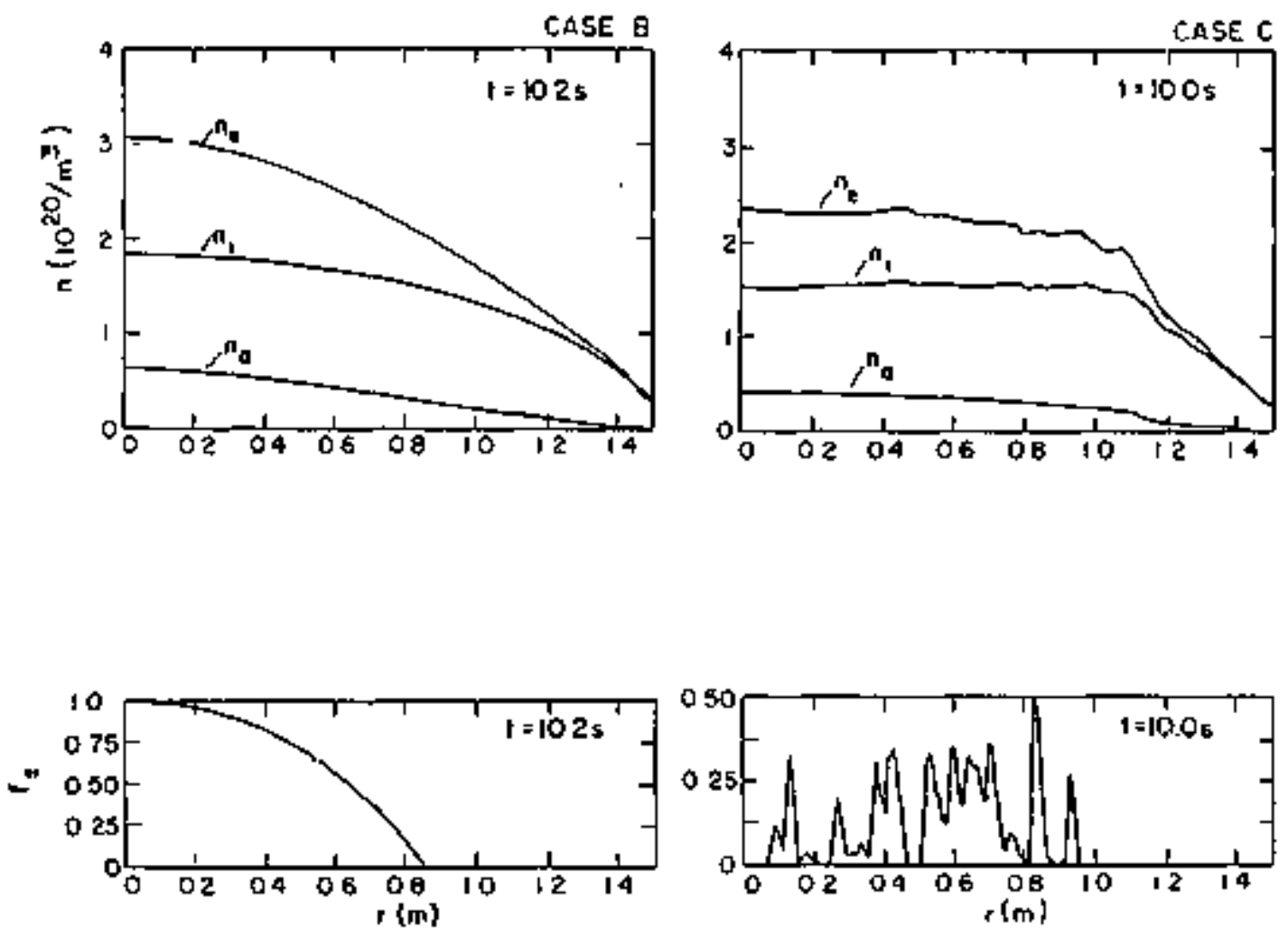

FIGJRE \&

Compartson of Case $B$ (no turbulence) and Case $C$ (with turbulence) one-dimensional stimuiations in terms of density and $f_{s}$ profiles that have evolved at $-10 \mathrm{~s}$ into the burn phase. 
of weak shear. These results indicate that a major part of the plasma confinement is provided by the plasma edge regions.

The magnetic fields maintain a continuous toporogical structure despite the enhanced transport associated with the Case $C$ model. Aberrations in both field and pitch parameter profiles are sma?l compared to density perturbations (Figs. 7,8 ). This result is characteristic of anomalous transport scaling through only the perpendicular resistivity, $n_{\perp}$ (Eqs. (13) and (14)).

Despite the significant differences in transport models used in Cases $B$ and $C$, the plasma $Q_{p}$ is increased only 10-20\% from the case $A$ comparison case. A factor of 1.3 then separates the predictions of the one-dimensional and zero-dimensional models.

C. Optimization of RFPR Design Point by One-Dimensional Model

The optimization of the RFPR design point by the onedimensional model is the primary motivation for this study. Overall reactor system considerations are not within the scope of this work, and a comparison with the point model is used to gauge if the predictions of the one-dimensional model are favorable. Establishing a 14.1-MeV neutron wall loading near the reference design' (2.7 $\left.\mathrm{MW} / \mathrm{m}^{2}\right)$, while maintaining a similar power output, fixes the plasma line density at $1.5(10)^{21}$ m $^{-1}$.

Using case D (with fixed radius) listed fn Table $V$, the magnetic fieid leveis were reduced to increase $Q_{p}$ (see Fig. 9). If $B_{\phi 0}$ is reduced below $\sim 5.8$ t, plasma ignition does not occur due to insufficient ohnic heating. As noted in Fig. 9, the poloidal beta increases from 0.39 to $0.5 ?$ as the magnetic fields are reduced, still remaining within stability limits as predicted by ideat MHO theory. 


\section{TABLE $V$}

COMPARISON OF EIEERGY BALANCE FOR ZERO- AND OPTIMIZED

ONE-DTME ISS IONAL BURN MODELS

\begin{tabular}{|c|c|c|}
\hline PARAMETER $(M \mathrm{~W} / \mathrm{m})$ & $\underline{\text { ZERO-D }}$ & $\begin{array}{r}\text { ONE - } \text { Pf }^{\mathrm{A}} \\
\text { C.ASE D } \\
\text { (OPTIMIZED) } \\
\end{array}$ \\
\hline Burn tige $\tau_{B}(s)$ & 21.6 & 22.0 \\
\hline Initial plasma energy, $w_{p i}$ & 0.05 & 0.99 \\
\hline Final plasma energy, $W_{p f}$ & 2.5 & 3.68 \\
\hline Radiation energy, $W_{R A D}$ & 28.1 & 19.3 \\
\hline Ohmic heating energy, $\mathrm{W}_{\mathrm{OH}}$ & 7.1 & 8.93 \\
\hline Plasma energy loss (conduction). Wcold & 147.5 & 146.7 \\
\hline Plasma expansion energy, $W_{P V}$ & 0.7 & 0.0 \\
\hline $\begin{array}{l}\text { Magnetic-field energy inside first } \\
\text { wall at end of burn cycie, "Wf }\end{array}$ & 51.6 & 30.6 \\
\hline -Fusion Neutron Energy, W $(14.1 \mathrm{MeV})$ & 676.5 & 646.2 \\
\hline $\begin{array}{l}{ }^{*} Q_{p}=\text { (fusion energy)/(tohmic }+ \\
\text { field energy) }\end{array}$ & 14.4 & 20.4 \\
\hline
\end{tabular}




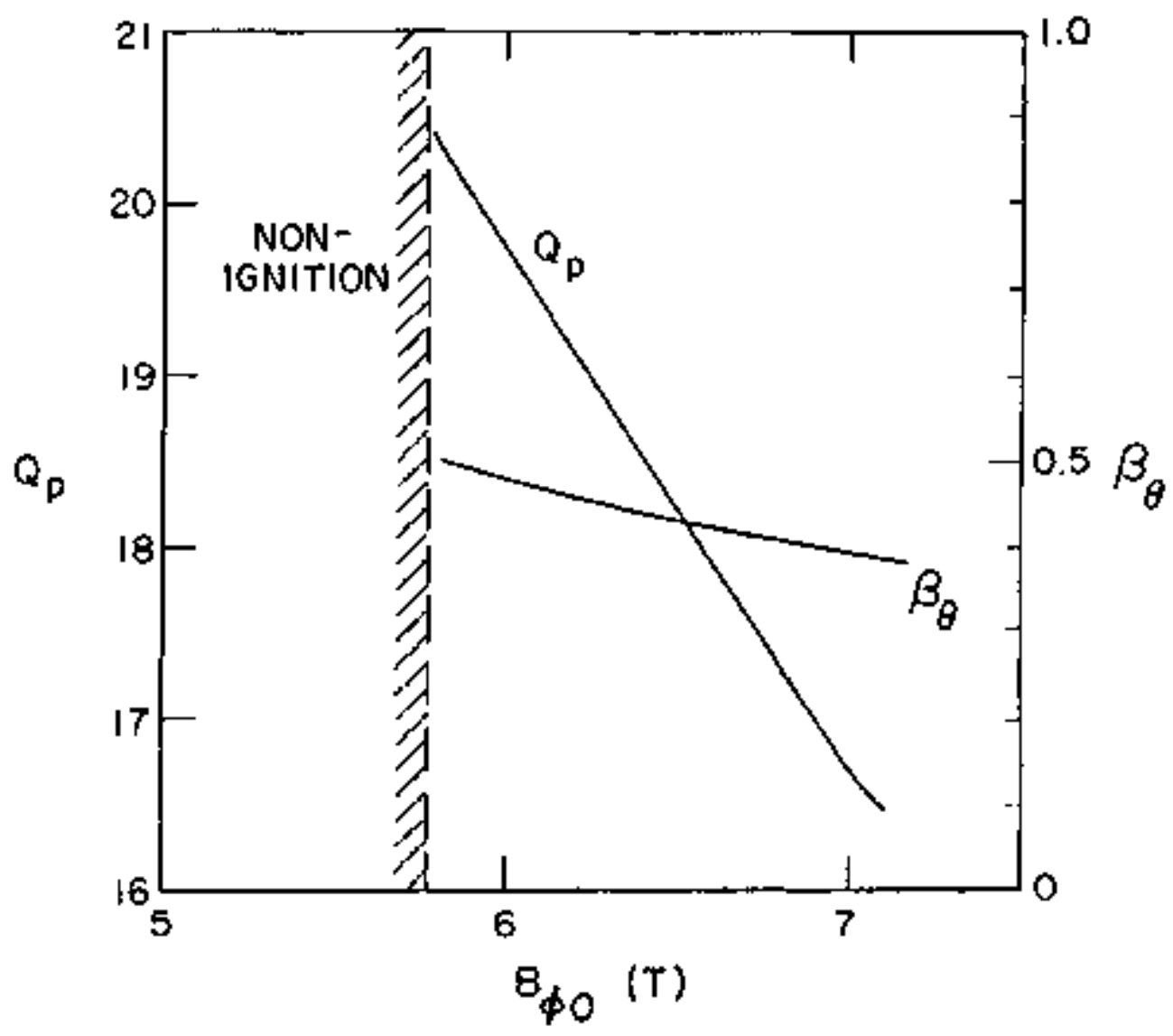

FIGURE 9

Dependence of plasma Q-values and associated maximum poloidal beta on the initial toroidal bias field. 
The time dependence of the electron and ion temperatures, $f_{B}$ and $B_{\theta}$ for the $Q_{D}=20.4$ case shom in Fig. 9 are plotted in Fig. 10. The plasma power fluxes are also given in Fig.' 10. The radial dependence of the magnetic fields is shown if Fig. 11 for $t=0,10,20 \mathrm{~s}$. At $t=0$ the plasma pressure is essentially zero, and the magnetic field profiles represent a pressureless plasma state. Expansion occurs as the plasma heats causing the magnetic fields near the center to decrease in order to maintain pressure balance. This behavior is iTlustrated by the $t=10 \mathrm{~s}$ case in Fig. 11 . Near the end of the burn (t 200 s) the plasma is agatr coot, and the fields relax toward the center. The effect of plasma expansion is also exhibited by the electron density profites depicted in Fig. 11.

The effects of fuel burnup are illustrated in Fig. 11 by the decreasing ion density and corresponding increase in alpha-particle density as the burn proceeds. Regions of Suydan instability viotation are shown in Fig. 11 as $f_{5}$. Only a small region of the plasma is initially unstable, but the region grows as the temperature is increased. The region of suydam instability is reduced as the plasma temperature decreases near the end of the burn $(t=20 \mathrm{~s}, \mathrm{Fig} .11)$, although relaxation of the profiles has also contributed to the degradation of the stability.

The existence of a turbulent Suydam-unstable central region is common to axisymmetric configurations (both the tokamaks and the RFP) and is not expected to limit severely the confinement properties because of the stable region between the turbulent plasma core and fịst wall. In fact, this study demonstrates that Suydam induced does not produce significantly different plasma perfomance from those 

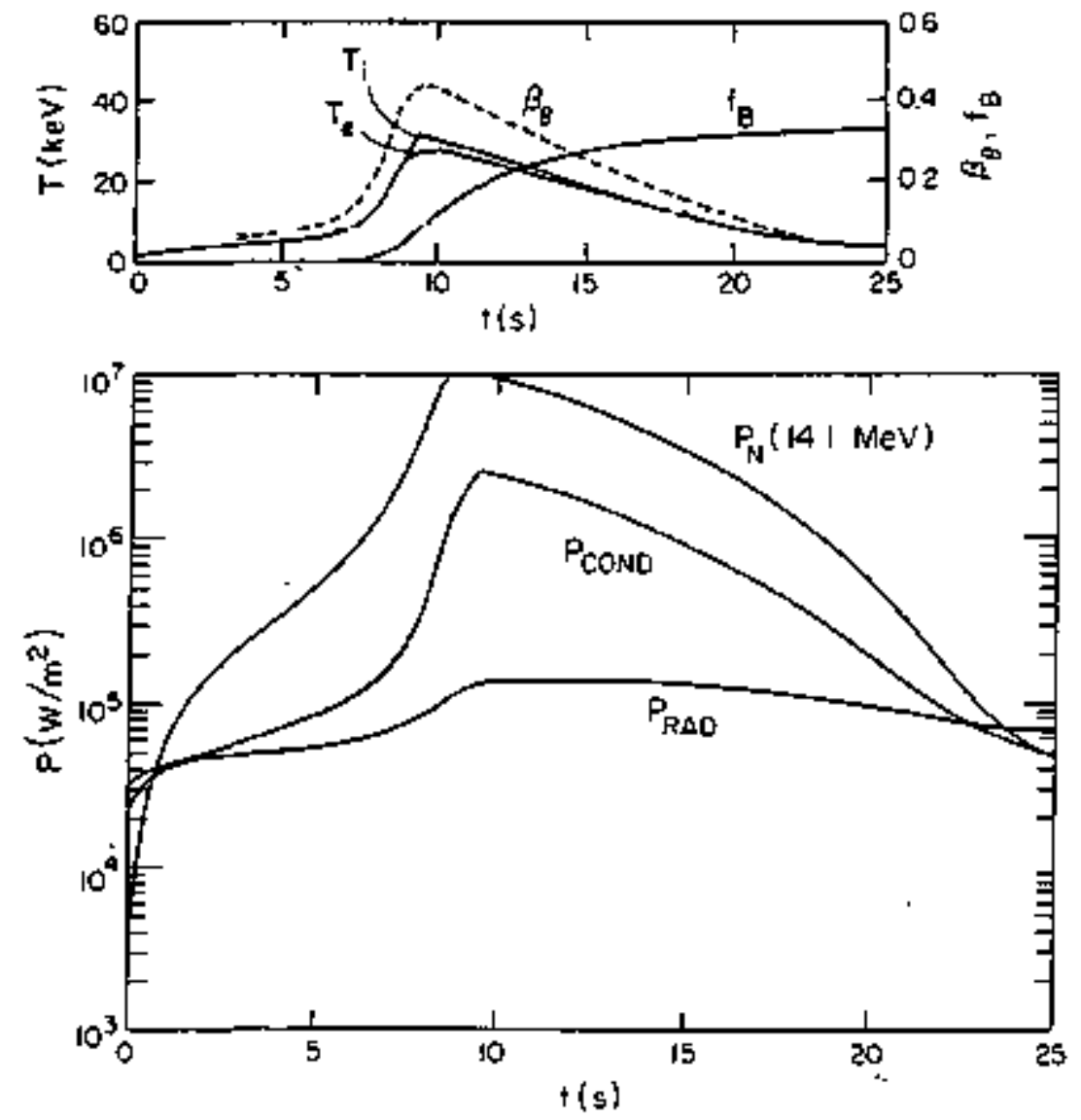

FIGURE 10

Time dependence of average plasma temperatures, beta, and OT fue $\dagger$ burnup fraction for the optimum design point. Also shown are the neutron, radiation and conduction powers expressed per unit first-wall area. 

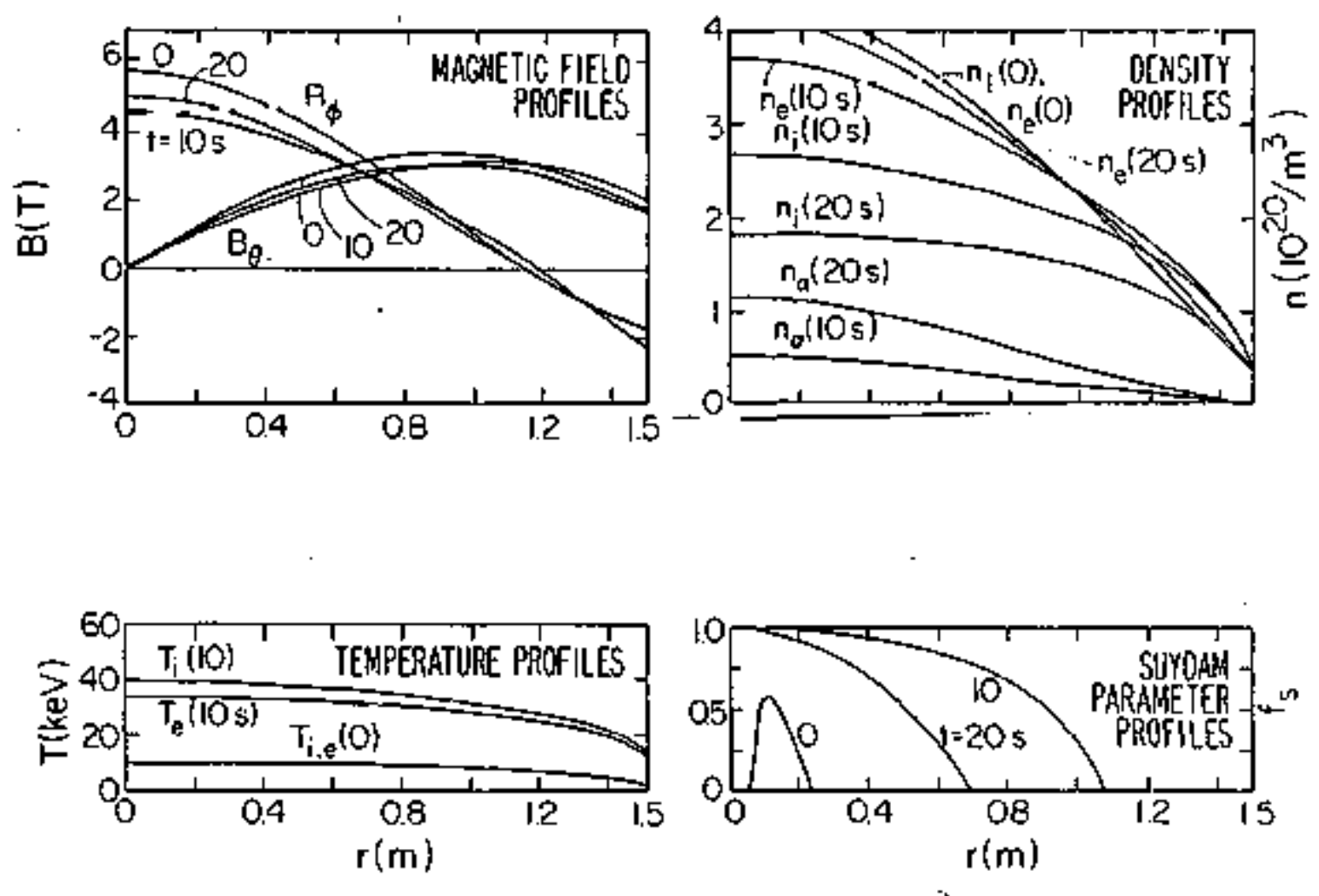

FIGURE II

Radial profiles of the magnetic fields, particle densities, fon and electron temperatures, magnetic field pitch and the Suydam stability parameter $\left(f_{s}\right)$ for the optimal design point at various times. 
cases in which the existence of the instability was onfy montored. The assumed anomalous energy confinement corresponding to $200 \mathrm{t}_{\mathrm{B}} \mathrm{OH}$ dominates any Suydam induced losses.

\section{v. CORCLUSTONS}

Generally, the one-dimensional model behaves similar to the point model. Differences between the results of the two modeis are caused by profile efferts.

One significant dffference is that local ignition and radial burn propagation allow the one dimensional model to fgnite with lower currents. This has led to a new optimized RFPR operating with better performance (higher $Q_{p}$ ) than was exhibited by the point model. The lower burnup exhibited by the one-dimensfonal model (Case A, Table III) is also caused by profile effects. Lower plasma edge temperature leads to lower burmup in that region causing a smaller total fractional burnup.

Stability studies indicate that gross plasma stability can be maintained with proper fieid programing for the ideal m=0 and $m=1$ modes. Suydan instabilities occur over a substantial region of the plasma, but tend to self-stabilize when anomalous transport is included. This transport flattens the density profiles and causes the plasma to approach the marginatiy stable Suydam limit. This results in stochastic viblation of Suydan's criterion in the inner plasma regions. However, this has little effect on gross plasina paraneters.

Although the one-dimensional simulations give considerably more insight into RFP reactor behavior, a number of physics questions rematn. Anong these questions are the empirical scaling of energy and 
particle transport; this will have to he resolved by experiment. Also, questions of startup and refueling for the RFP remain to be answered.

These will be addressed by a future study, involving extension of the one-dimensional model used here.

Acknowledguents:

The advice and collaboration of Dr. R. L. Hagenson and Dr. R. A. Krakowski is gratefully acknowledged.

\section{REFERENCES}

1. R. L. Hogenson, R. A. Krakowski, and G. E. Cort, "The ReversedField Pinch Reactor," Los Alamos Scientific Laboratory report LA7973-MS (August, 1979).

2. J. B. Taylor, "Relaxation of Toroidal Discharges," Third Topical Conference on Pulsed High Beta Plasmas, Culham, United Kingdam, p. $59,1975$.

3. D. Montgomery, L. Turner, and G. Vahala, "Three Dimensional Magnetohydrodynamic Turbulence in Cylindrical Geometry," Phys. Fiuids, 2\} $757-764(1978)$.

4. R. A. Nebel, G. H. Miley, and R. W. Moses, "Reversed-Field Pinch Burn Dynamics," IEEE Intern. Conf. on Plasma Science, p. 196, Montreal (1979).

5. 0. C. Robinson, "High-B Diffuse Pinch Configurations," Plasma Physics, 13, 434-462 (197]).

6. H. A. B. Bodin and A. A. Newton, "Rewerse Field Pinch Research," Huclear fusion preprint.

7. T. H. Stix, "Heating of Toroidal Plasmas by Neutral Injection," Plasma Physics, 14, 367 (1972).

8. B. R. Suydam, "Stability of a Linear Pinch," Proc. 2nd un Inter. Conf. on the Peacefu? Uses of Atomic Energy, 31, 157-159, Geneva, Switzerland (1958).

9. I. A. Newconb, "Hydromagnetic Stability of a Diffuse Linear Pinch," Annais of Physies, 10, 232-267 (1960).

10. J. P. Christiansen and K. $V$ Roberts, "Evolution of the ReversedField Pinch," Nuc1. Fusion, 18, 2, 181-197 (1978). 